\title{
A Functional Polymorphism of the $\mu$-Opioid Receptor Gene is Associated with Naltrexone Response in Alcohol-Dependent Patients
}

\author{
David W Oslin*, 1,2,3, Wade Berrettini ${ }^{3,4}$, Henry R Kranzler ${ }^{5}$, Helen Pettinati', Joel Gelernter ${ }^{6}$, Joseph R \\ Volpicelli' and Charles P O'Brien ${ }^{1,2}$ \\ 'Center for the Study of Addictions, Department of Psychiatry, University of Pennsylvania, Philadelphia, PA, USA; ${ }^{2}$ Mental IIIness Research, \\ Educational, and Clinical Center (MIRECC) at the Philadelphia VA Medical Center, USA; ${ }^{3}$ Section of Geriatric Psychiatry, Department of \\ Psychiatry, University of Pennsylvania, Philadelphia, PA, USA; ${ }^{4}$ Center for Neurobiology and Behavior, Department of Psychiatry, University of \\ Pennsylvania, Philadelphia, PA, USA; ${ }^{5}$ Alcohol Research Center, Department of Psychiatry, University of Connecticut School of Medicine, USA; \\ ${ }^{6}$ Department of Psychiatry, Yale University School of Medicine and Psychiatry Service, VA Connecticut Healthcare System, USA
}

\begin{abstract}
This study examined the association between two specific polymorphisms of the gene encoding the $\mu$-opioid receptor and treatment outcomes in alcohol-dependent patients who were prescribed naltrexone or placebo. A total of 82 patients (7I of European descent) who were randomized to naltrexone and 59 who were randomized to placebo (all of European descent) in one of three randomized, placebo-controlled clinical trials of naltrexone were genotyped at the $A_{+118} G$ (Asn40Asp) and $C_{+17}$ (Ala6Val) SNPs in the gene encoding the $\mu$-opioid receptor (OPRMI). The association between genotype and drinking outcomes was measured over 12 weeks of treatment. In subjects of European descent, individuals with one or two copies of the Asp40 allele treated with naltrexone had significantly lower rates of relapse $(p=0.044)$ and a longer time to return to heavy drinking $(p=0.040)$ than those homozygous for the Asn40 allele. There were no differences in overall abstinence rates $(p=0.6 \mathrm{I})$, nor were there differences in relapse rates or abstinence rates between the two genotype groups among those assigned to placebo. These preliminary results are consistent with prior literature demonstrating that the opioid system is involved in the reinforcing properties of alcohol and that allelic variation at OPRMI is associated with differential response to a $\mu$-receptor antagonist. If replicated, these results would help to identify alcohol-dependent individuals who may be most likely to respond to treatment with naltrexone.

Neuropsychopharmacology (2003) 28, I546-1552, advance online publication, 18 June 2003; doi: I0.1038/sj.npp. I 300219
\end{abstract}

Keywords: alcoholism; naltrexone; genetics; treatment; pharmacology

\section{INTRODUCTION}

Alcohol dependence is one of the leading causes of disability worldwide (Murray and Lopez, 1996). In an effort to reduce the morbidity and mortality associated with the disorder, there has been widespread interest in improving its treatment. Based on animal studies showing an effect of alcohol on the endogenous opioid system, Volpicelli et al $(1990,1992)$ tested the efficacy of the opioid receptor antagonist naltrexone to enhance psychosocial rehabilitation of alcohol dependence. The beneficial effect of naltrexone observed by these investigators was indepen-

\footnotetext{
*Correspondence: Dr D Oslin, University of Pennsylvania, 3535 Market Street, Room 3002, Philadelphia, PA 19104, USA, Tel: + I 215 6153083, Fax: + I 215 349-8389, E-mail: oslin@mail.med.upenn.edu Received 08 January 2003; revised 03 April 2003; accepted 16 April 2003

Online publication: 23 April 2003 at http://www.acnp.org/citations/ Npp04230 I/default.pdf
}

dently replicated (O'Malley et al, 1992), leading to approval of the medication by the US Food and Drug Administration for treatment of alcohol dependence. Since that time, the majority of clinical trials have established the benefits of naltrexone in the treatment of alcoholism (Oslin et al, 1997; Chick et al, 2000; Anton et al, 2001; Monterosso et al, 2001; Monti et al, 2001; Morris et al, 2001). The use of naltrexone is based on an endorphin compensation model, suggesting that some alcohol-dependent individuals sustain a relative deficiency in endogenous opioids after experiencing a stressful event (Volpicelli, 1987; Volpicelli et al, 1990; Kreek, 1996). Alcohol has been found to increase endogenous opioids, especially in people with a family history of alcoholism (Gianoulakis, 1996). This mechanism may account for a part of the reinforcement of alcohol drinking. Naltrexone has also been reported to block the euphoria produced by alcohol (Volpicelli et al, 1995; King et al, 1997). Thus, the endogenous opioid system is involved in the reinforcement of alcohol use. Presumably by blocking this 
reinforcement, naltrexone can aid in the treatment of alcoholism.

Although the majority of samples studied have shown a significant advantage of naltrexone over placebo (O'Malley et al, 1992; Volpicelli et al, 1992; Oslin et al, 1997; Chick et al, 2000; Anton et al, 2001; Monti et al, 2001; Morris et al, 2001), other studies have failed to show a significant drugplacebo difference (Kranzler et al, 2000; Krystal et al, 2001). Clearly, naltrexone does not help all alcohol-dependent adults and not all persons who drink alcohol show evidence of a 'high' (King et al, 1997) or an increase in endogenous opioids (Gianoulakis et al, 1996) induced by alcohol consumption. The lack of efficacy of naltrexone in some alcohol-dependent patients has led to investigations that focus on questions regarding which patients are most benefited by this treatment. Indeed, some clinical trials have shown family history to be a predictor of treatment response (Jaffe et al, 1996; Monterosso et al, 2001).

The role of family history as a predictor of treatment response has led to speculation that naltrexone may function differently in genetically predisposed individuals. Naltrexone has high affinity for the $\mu$-opioid receptor, which is hypothesized to be the principal site of action of the medication. It has been hypothesized that sequence variation in the gene encoding the $\mu$-receptor (genetic locus OPRM1), may result in a receptor with altered expression, structure or function, and as a consequence, increase or decrease an individual's susceptibility to substance dependence (Lichtermann et al, 2000). In particular, two polymorphisms in exon 1 of the gene alter amino acid sequence, $A_{+118} \mathrm{G}$ (Asn40Asp) and $\mathrm{C}_{+17} \mathrm{~T}$ (Ala6Val), and these have received the most research attention. However, case-control studies have failed to demonstrate a consistent association between OPRM1 sequence variation and the presence of alcohol and/or drug dependence (Bergen et al, 1997; Berrettini et al, 1997; Bond et al, 1998; Kranzler et al, 1998; Sander et al, 1998; Gelernter et al, 1999; Town et al, 1999; Hoehe et al, 2000; Franke et al, 2001; Rommelspacher et al, 2001; Szeto et al, 2001; Schinka et al, 2002; Crowley et al, 2003).

Despite the lack of consistent evidence for association between OPRM1 exon 1 polymorphisms and alcohol dependence, it is possible that one or both of these polymorphisms moderate treatment response to opioid receptor blockade. That is, the response to treatment may be independent of the phenotype of alcohol dependence per se. In this respect, the $\mathrm{A}_{+118} \mathrm{G}$ polymorphism is of particular interest, since functional effects of the polymorphism have been demonstrated both in vitro and in vivo. Bond et al (1998) showed that, in cell culture, $\mu$-opioid receptors encoded by the Asp40 variant bind $\beta$-endorphin and activate G-protein-coupled protein potassium ion channels with three times greater potency than receptors encoded by the Asn 40 variant. Both Wand et al (2002) and Hernandez-Avila et al (2003) found that individuals with one or two copies of the Asp40 allele had altered HPA-axis activation induced by the opioid receptor antagonist naloxone, while Smolka et al (1999) showed that individuals with the Asp40 variant display greater dopaminergic sensitivity during acute alcohol withdrawal.

The present study was undertaken to examine the association between drinking outcomes and the Asn40Asp and Ala6Val polymorphisms among patients who were treated with naltrexone or placebo. Consistent with evidence of greater effects of naloxone among subjects with the Asp40 variant, we hypothesized that this allele would predict greater clinical response among patients who underwent naltrexone treatment for a minimum of 5 weeks. At least one copy of the Asp40 variant is expected to be present in $24.3-36 \%$ of the general population of adults of European descent (Bergen et al, 1997; Bond et al, 1998; Gelernter et al, 1999; Crowley et al, 2003). Consequently, this polymorphism is also of potential importance on an epidemiological level, since the allele is sufficiently common to be clinically relevant if associated with treatment response.

\section{METHODS}

\section{Study Sample}

Subjects were participants in one of three randomized, placebo-controlled clinical trials of naltrexone for the treatment of alcohol dependence. The specific procedures for the studies have been detailed in prior publications (Kranzler et al, 2000; Monterosso et al, 2001) and are briefly outlined here. Recruitment for the first study (study I) was conducted from January 1996 until January 1998 at the University of Pennsylvania (Monterosso et al, 2001). In study I, 183 outpatients were randomized to one of three conditions; 9 months of naltrexone $100 \mathrm{mg} /$ day, 12 weeks of naltrexone $100 \mathrm{mg} /$ day followed by 6 months of placebo, or 9 months of placebo. All subjects received the same psychosocial intervention focused on medication adherence and education and support in the recovery from alcohol dependence (BRENDA) (Volpicelli et al, 1997). The second study (study II) (results unpublished) was conducted from May 1998 until June 2002 at the University of Pennsylvania. A total of 240 subjects were randomly assigned to 24 weeks of naltrexone $100 \mathrm{mg} /$ day or placebo and randomized to one of three different psychosocial interventions; cognitivebehavioral therapy (CBT), BRENDA, or simple medication management by a physician. The third study (study III), which involved 1 week of single-blind placebo treatment followed by 11 weeks of double-blind treatment, was conducted at the University of Connecticut Health Center between October 1993 and November 1996 (Kranzler et al, $2000)$. Subjects $(n=183)$ were randomly assigned to receive naltrexone ( $50 \mathrm{mg} /$ day), nefazodone (up to a maximum of $600 \mathrm{mg} /$ day) or placebo in conjunction with CBT.

Study participants for each of the treatment trials were recruited through advertisements in the local media. Eligible subjects had to be at least 18 years of age, meet DSM-III-R or DSM-IV criteria for alcohol dependence, and successfully complete detoxification from alcohol, as defined by a minimum of 3 consecutive days of abstinence prior to the start of the study medication. Subjects were not included if they had a current diagnosis of any psychoactive substance dependence other than alcohol or nicotine dependence or had evidence of opiate use in the past 30 days as assessed both by self-report and urine drug screen at admission to treatment. Subjects were excluded from the study if they were taking psychotropic medications, had evidence of current severe psychiatric symptoms, or of 
significant hepatocellular injury. Each study was reviewed and approved by the Institutional Review Board at the host site and all subjects provided written informed consent prior to study participation.

In studies I and II, beginning in the fifth week of treatment, all the subjects were invited to participate in a study of the genetics of alcohol dependence. Participation in the genetics substudy necessitated a written informed consent process that was separate from the consent to participate in the clinical trial. In study III, the subjects were invited to participate in the genetics substudy at the start of the trial, and a separate consent process was not required. For the purpose of examining the genetics of naltrexone response, we limited our analysis to those subjects with well-defined outcome data, who had what was deemed an adequate exposure to the treatment. Thus, inclusion criteria for the pharmacogenetic study included subjects who consented to genotyping, and who participated in the double-blind treatment for at least 5 weeks. Although other criteria of exposure could be proposed, our goal was to define a group of subjects with an adequate exposure to study treatment. These inclusion criteria also eliminated some of the variability in sampling procedures across the three studies.

\section{Assessment Instruments}

Outcome measures were obtained prior to study entry and weekly or bimonthly throughout each trial by research assistants not directly involved in the treatment of subjects and who were blind to medication group. For the purposes of this study, we focused on outcomes during the first 12 weeks of study participation. Medication was provided weekly. Adherence to the study medication regimen was monitored by self-report of medication use and by pill counts confirmed by weekly qualitative measurement of riboflavin (DelBoca et al, 1996). The Addiction Severity Index (ASI) was used to measure the severity of alcoholrelated problems during the pretreatment period (McLellan et al, 1980, 1992). The ASI is a $1 \mathrm{~h}$, structured interview that measures the lifetime and recent (past 30 days) severity of problems in seven areas of biopsychosocial functioning (represented by component scores): medical status, employment and self-support, alcohol use, drug use, legal status, family and social relations, and psychiatric symptoms (McLellan et al, 1985). The Time Line Follow-Back (TLFB) method measured alcohol consumption (Sobell et al, 1988; Sobell and Sobell, 1992) during the pretreatment and treatment periods. The TLFB is a semi-structured interview that uses a calendar format to record the quantity and frequency of drinking during a stated period of time. In this instance, drinking reports were recorded for the 90 days preceding detoxification, as well as during the study period. The quantity of alcohol was recorded in standard drinks (eg a $12-\mathrm{oz}$ beer, a $5-\mathrm{oz}$ glass of wine, or $1 \frac{1}{2}-\mathrm{oz}$ distilled spirits $=$ one standard drink).

The primary drinking outcome considered was relapse to heavy drinking $(\geqslant 5$ drinks in a single day for men or $\geqslant 4$ drinks for women). Although this definition of heavy drinking has been used in a number of pharmacotherapy trials (O'Malley et al, 1992; Volpicelli et al, 1992; Anton, 1996; Kranzler and VanKirk, 2001), both higher and lower levels of consumption could be considered significant. This outcome was also among the primary hypothesized outcomes for each of the trials. Three subjects dropped out of the study prior to the end of 12 weeks and were unavailable for all assessments. However, all three had relapsed prior to discontinuing their participation in the trial and their data were used in the response analyses.

\section{Genotyping}

Approximately $20 \mathrm{ml}$ of EDTA-treated venous blood were obtained for DNA extraction from each subject. Genomic DNA was extracted from blood samples by standard methods (eg Lahiri and Schnabel, 1993). The $\mathrm{C}_{+17} \mathrm{~T}$ and $\mathrm{A}_{+118} \mathrm{G}$ SNPs were genotyped using the PCR-RFLP method of Gelernter et al (1999). Genotyping was conducted in batches according to each of the studies. For each batch of genotyping, five DNA samples were genotyped in duplicate, and no discordant genotypes were generated.

\section{Statistical Analysis}

Statistical analyses used SPSS for Windows, Version 11.0. Descriptive analyses included means and standard deviations for continuous variables and frequencies for categorical variables. For comparisons between groups, continuous variables were compared using analysis of variance and categorical variables were compared using a chi-square test. Subjects either heterozygous or homozygous for the Asp40 variant were considered together as there was only one subject in this sample who was homozygous for this allele. Logistic regression analyses were applied to assess the relation between genotype and the principal outcome of relapse, with pretreatment drinking variables, marital status, age $(\geqslant 55)$, study origin, type of psychotherapy, and gender serving as covariates. Cox regression analyses were constructed using the same covariates as used in the regression analyses to assess the effects of genotype on the time to relapse to heavy drinking. To explore medication by genotype interactions, we created a single variable representing the four possible groups and tested for differences among them. As the frequency distribution in the general population of the $\mathrm{C}_{+17} \mathrm{~T}$ and $\mathrm{A}_{+118} \mathrm{G}$ SNPs differs significantly by ethnic origin (Gelernter et al, 1999), with few African Americans (AAs) having the $A_{+118}$ G SNP and few European Americans (EAs) having the $\mathrm{C}_{+17} \mathrm{~T}$ SNP, analyses were limited to the allele of interest in each ethnic group examined separately.

\section{RESULTS}

Among the three clinical trials, 260 subjects were randomly assigned to receive naltrexone and 206 were assigned to placebo, with both groups also receiving psychotherapy. Of this number, 98 naltrexone-treated subjects and 63 placebotreated subjects consented to having their DNA collected. In all, 15 naltrexone-treated and five placebo-treated subjects (all from study III, which recruited from the start of the trial) did not meet the minimum criteria for exposure to treatment (five naltrexone and one placebo subjects had the Asp40 variant). Of the 141 subjects eligible for this study, 71 naltrexone-treated and 59 placebo-treated subjects were EA 
and 11 naltrexone-treated subjects were AA. Of the EA subjects treated with naltrexone, 25 were from study I, 19 were from study II, and 27 were from study III and of the EA subjects treated with placebo, 21 were from study II and 38 were from study III. Given the small number of AAs, only descriptive results from these subjects are presented.

Table 1 presents the baseline demographic, psychosocial, and drinking severity information for the EA sample by genotype at the $A_{+118} G$ SNP. Overall, the EA sample was primarily (79.2\%) male, with an average age of 46.2 years $(\mathrm{SD}=11.5)$ and $40.3 \%$ of the sample was currently married. There were no significant differences between naltrexoneand placebo-treated subjects homozygous for the Asn 40 and those with the Asp40 variant (ie heterozygotes or homozygotes) on any of the demographic or clinical variables at the time of treatment entry. That there were more placebotreated subjects receiving CBT therapy reflected the lack of inclusion in the analysis of subjects from study I, which used BRENDA therapy only. AA subjects were also mostly male (81.8\%) and married (54.5\%), with an average age of 44.7 years $(\mathrm{SD}=10.9)$. The Val6 variant occurred in five of the AAs (45.5\%), with none being homozygous for this variant. As expected, no AAs had the Asp40 variant of the $\mathrm{A}_{+118} \mathrm{G}$ SNP and none of the EAs had the Val6 variant of the $\mathrm{C}_{+17} \mathrm{~T}$ SNP, which are consistent with previously reported allele frequencies in those populations.

As expected, given the inclusion criteria, EAs had high rates of adherence to medication $(92.5 \%$ of the prescribed medication was taken). Similarly, $81.8 \%$ of AAs were highly adherent to medication. There were no differences between naltrexone-treated or placebo-treated EAs homozygous for the Asn 40 allele and those with one or more Asp40 alleles on the average number of days taking medication $(\mathrm{F}=0.473$, $p=0.702$ ). There was a significantly greater proportion of naltrexone-treated subjects with the Asp40 variant who did not return to heavy drinking (no relapse) compared to those who were homozygous for the Asn 40 allele (Wald $=4.05,1$ df, OR $=3.52$ (95\% CI: 1.03-11.96), $p=0.044$ ) (see Table 2). However, there was no difference in the rates of abstinence between subjects in these groups (Wald $=0.259,1 \mathrm{df}$, $\mathrm{OR}=0.76(95 \%$ CI: $0.27-2.16), p=0.611)$. There was no significant difference in the proportion of placebo-treated subjects with the Asp40 variant who did not return to heavy drinking (no relapse) compared to those homozygous for the Asn 40 allele (Wald $=0.415,1 \mathrm{df}, \mathrm{OR}=1.15$ (95\% CI: $0.43-5.35), p=0.534)$. There was also no difference in the rate of abstinence between placebo-treated subjects in these groups (Wald $=0.14,1 \mathrm{df}, \mathrm{OR}=0.78$ (95\% CI: $0.22-2.80$ ), $p=0.705)$. Despite the main effect of genotype in the naltrexone-treated group, there was no medication by genotype interaction on relapse rates (Wald $=0.97,1 \mathrm{df}$, $\mathrm{OR}=2.27$ (95\% CI: $0.44,11.60), p=0.326)$. There was also no medication by genotype interaction for abstinence (Wald $=0.02, \quad 1 \quad$ df, $\quad$ OR $=0.89 \quad(95 \% \quad$ CI: $\quad 0.18,4.38)$, $p=0.889$ ). Of note, there was a significant effect of naltrexone in reducing rates of relapse in the overall pooled sample even when genotype was included in the regression analysis (Wald $=4.70,1 \mathrm{df}, \mathrm{OR}=2.42$ (95\% CI: 1.09, 5.39), $p=0.030)$.

Consistent with the finding concerning likelihood of relapse, the time to first relapse in the naltrexone-treated subjects was significantly longer in those with the Asp40 variant $($ Wald $=4.22,1 \mathrm{df}, \mathrm{OR}=2.79(1.05,7.41), p=0.040)$ (see Figure 1). The time to first relapse for the placebotreated subjects was not significantly longer in those with the Asp40 variant (Wald $=0.725,1 \mathrm{df}, \quad \mathrm{OR}=1.41$ $(0.64,3.09), p=0.394)$. However, there was no significant medication by genotype interaction (Wald $=1.737,1 \mathrm{df}$, $\mathrm{OR}=0.44(0.13,1.50), p=0.188)$.

Among AAs, four of six subjects who were homozygous for the Ala6 variant did not return to heavy drinking (no relapse) and three of five heterozygous subjects did not relapse. Rates of abstinence in the homozygous group were three of six and two of five, respectively.

\section{DISCUSSION}

The results of this trial provide preliminary evidence of an association between variation at the $\mu$-opioid receptor gene locus and therapeutic response to naltrexone treatment for alcohol dependence. If replicated in a larger and less selected sample, these findings may help to explain some of the variability in response to naltrexone seen both clinically

Table I Baseline Demographics and Clinical Characteristics of the Study Participants

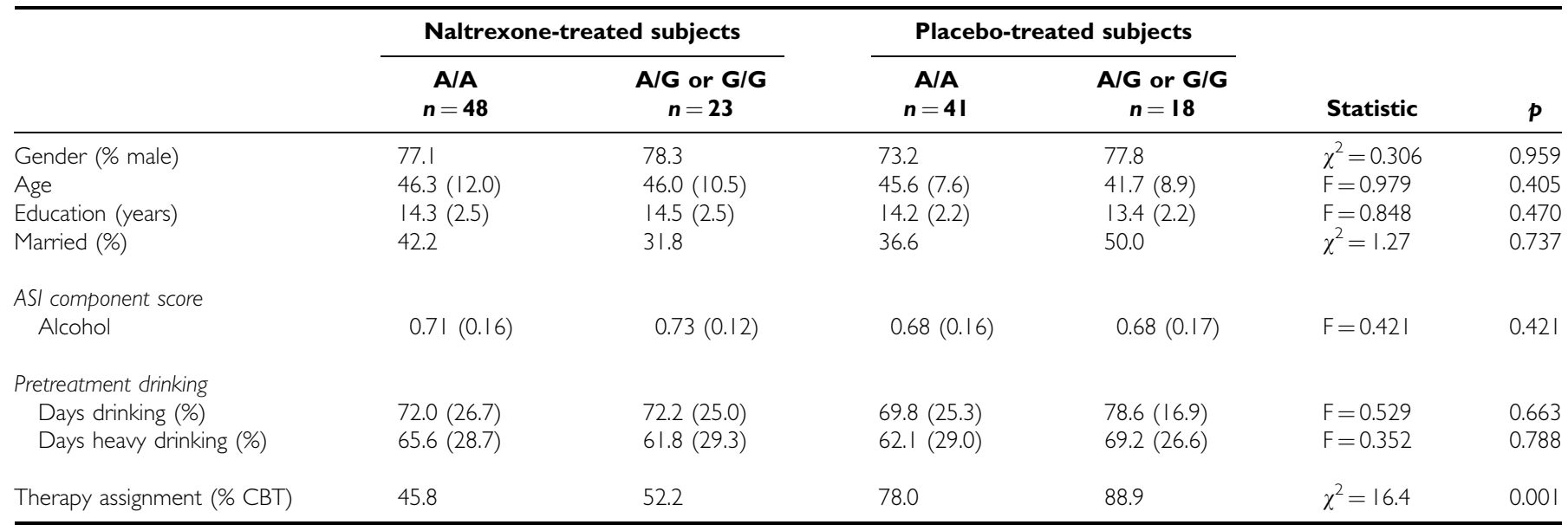

Values represent means (standard deviations) for continuous measures and percentages for categorical measures. All tests have $3 \mathrm{df}$. 
Table 2 Proportions of Clinical Response in Relation to the Genetic Polymorphism at the $A_{+||}$G SNP among Patients of European Descent Treated with Naltrexone

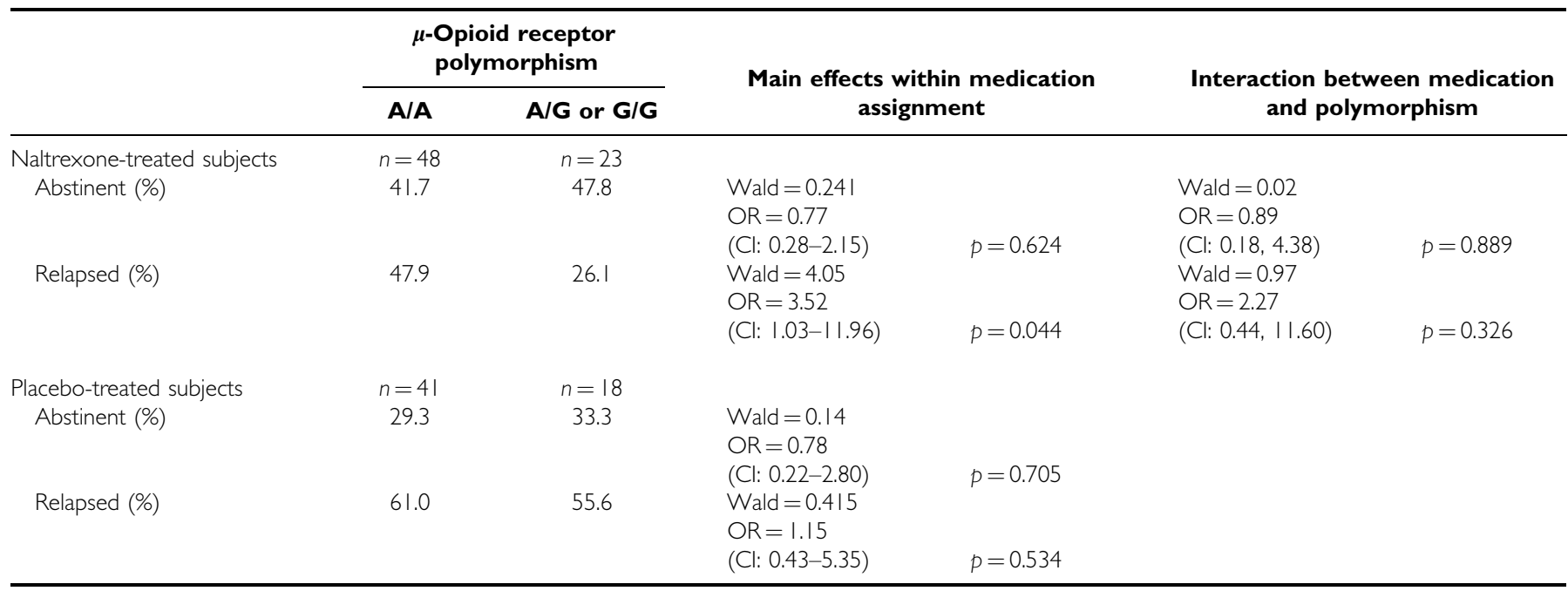

Values represent percentages for categorical measures. Logistic regressions were used for categorical outcomes with I $\mathrm{df}$ and $95 \% \mathrm{Cl}$.

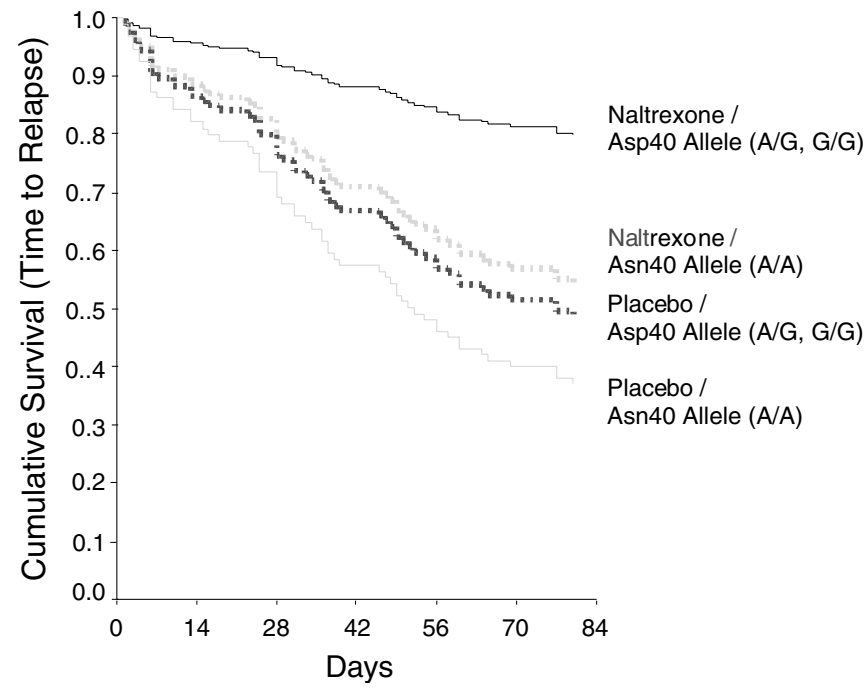

Figure I Survival analyses for time to relapse in subjects with one or two copies of the Asp40 allele vs those homozygous for the Asn40 allele by medication group.

and in clinical trials. Although the efficacy of naltrexone has been established in a number of randomized clinical trials, no trial has demonstrated efficacy for all subjects and, overall, the published clinical trials demonstrate only modest response effect sizes (Kranzler and VanKirk, 2001; Streeton and Whelan, 2001). This lack of marked effects has been one of the reasons cited by providers to explain the relatively low utilization of naltrexone in clinical settings (Thomas et al, 2001). Examination of the heterogeneity of responses is justified in order to improve the utilization of naltrexone and to enhance the efficiency of its use in the treatment of alcohol dependence.

It is worth noting that two of the clinical trials in which these data were collected demonstrated modest efficacy of naltrexone when examining the entire sample regardless of genotype, with study III reporting no overall efficacy of naltrexone. Moreover, subjects homozygous for the Asn40 allele showed relapse rates on naltrexone $(51.0 \%)$ that were only marginally better than those reported for placebo in combination with psychotherapy (O'Malley et al, 1992; Monterosso et al, 2001). The lack of a moderating genetic effect among the placebo-treated subjects is supportive of the hypothesis that this polymorphism has a specific effect on naltrexone response. Although in this sample, the tests for interactive effects of medication and genotype did not reach statistical significance, they were in the direction of supporting a specific effect. The lack of a medication by genotype interaction is possibly explained by the small size of the Asp40 group as well as a strong overall medication effect in this sample of highly treatment-adherent subjects.

These findings are also consistent with a growing literature on the role of the opioid system in alcohol dependence and the functional differences associated with the Asp40 gene variant. Prior animal and human studies have demonstrated that the opioid system is involved in the reinforcing effects of alcohol (Volpicelli et al, 1986, 1990; Kreek, 1996). Indeed, it was this basic work that led to the hypothesis that naltrexone might be clinically useful in treating alcohol dependence, hence the development of naltrexone is a good example of translational neuroscience. Examining the effects of alcohol consumption and naltrexone in high-risk individuals has further supported the idea that there may be a relative lack of basal $\beta$-endorphin release and that the opioid system is more sensitive to alcohol among high-risk subjects (Gianoulakis, 1996; Gianoulakis et al, 1996). Subjectively, some fraction of the rewarding effects of alcohol ingestion in high-risk subjects can be blocked by naltrexone (King et al, 1997). Moreover, Wand et al $(1998,2002)$ found that both family history and the Asp40 variant explained some variance in the release of corticotrophin-releasing factor (CRF) after stimulation with naloxone. Taken together, these findings suggest a possible mechanism for naltrexone response in which the clinical 
effects of the drug on reducing alcohol consumption may be enhanced in those with the Asp40 genotype, while having only marginal efficacy in those homozygous for the Asn 40 variant. Given that naltrexone also has efficacy in AA populations, it is also plausible that other functionally active OPRM1 variants may occur among patients of nonEuropean descent.

Although the findings from this study appear to be consistent with the literature and they help to explain clinical findings in relation to naltrexone response, several limitations of this study should be noted. First, the sample size for this trial is relatively small and the studies from which the sample was acquired were not designed specifically to address issues of genetic vulnerability. As such, the results should be considered preliminary and efforts should be made to evaluate the hypothesis in trials designed to address these shortcomings. For instance, because of design issues, we were unable to examine the relation between OPRM1 genotype and family history of alcohol dependence, as data on the latter variable were not collected in sufficient detail. Similarly, because of the timing of collection of the genetic samples and the voluntary nature of the collection, we are unable to estimate the proportion of patients with the Asp40 genotype who were randomized to naltrexone, but were nonadherent to the medication in the earlier stages of the trial. In order to achieve some uniformity in sample collection, we restricted the sample in study III to those who had been in the trial for more than 5 weeks. However, differences in trial design also limit the interpretation of findings. We also note that the presence of adverse effects early in treatment may affect treatment adherence and result in sampling bias that was not addressed in this study (Kranzler et al, 2000).

Finally, although at least one copy of the Asp40 allele is present in $24-36 \%$ of EAs, AAs $<1 \%$ have at least one copy of the Asp40 allele. Since prior clinical trials that have included a substantial proportion of AAs have not shown an effect of ethnicity on treatment response (Volpicelli et al, 1992; Oslin et al, 1997; Monterosso et al, 2001), there may be additional genetic predictors associated with naltrexone treatment response in this population. Unfortunately, the number of subjects in the present study was too small to examine the effects of the $\mathrm{C}_{+17} \mathrm{~T}$ SNP and, at this time the functional significance of the $\mathrm{C}_{+{ }_{17} \mathrm{~T}} \mathrm{SNP}$ has not been demonstrated. Further pharmacogenetic research on the response to naltrexone among AAs is required.

If the findings reported here are replicated, OPRM1 genotyping may prove to be an efficient mechanism for identifying patients who are most likely to respond to naltrexone and those for whom other available treatments may be more efficacious. Such a pharmacogenetic approach to treatment has economic implications by increasing the cost-effectiveness of patient-treatment matching. Perhaps, more importantly, such an approach could also reduce the likelihood of exposing patients unnecessarily to a medication that will be ineffective for them.

\section{ACKNOWLEDGEMENTS}

We certify that there are no conflicts of interest, financial or otherwise, in the preparation of this manuscript. Supported, in part, by grants from the Mental Illness Research, Education, and Clinical Center (MIRECC) at the Philadelphia Veterans Affairs Medical Center. NIH Grants AA07517, AA11062, AA13736, AA03510, AA11330, RR06192, DA11835, DA14008, DA001586, and MH01599, VA Connecticut-Massachusetts Mental Illness Research, Education, and Clinical Center (MIRECC).

\section{REFERENCES}

Anton RF (1996). New methodologies for pharmacological treatment trials for alcohol dependence. Alcoholism: Clin Exp Res 20: 3A-9A.

Anton RF, Moak DH, Latham PK, Waid LR, Malcolm RJ, Dias JK et al (2001). Posttreatment results of combining naltrexone with cognitive-behavior therapy for the treatment of alcoholism. $J$ Clin Psychopharmacol 21: 72-77.

Bergen A, Kokoszka J, Peterson R, Long J, Virkkunen M, Linnoila $\mathrm{M}$ et al (1997). Mu-opioid receptor gene variants: lack of association with alcohol dependence. Mol Psychiatry 2: 490-494.

Berrettini W, Hoehe M, Ferraro T, DeMaria P, Gottheil E (1997). Human mu opioid receptor gene polymorphisms and vulnerability to substance abuse. Addict Biol 2: 303-308.

Bond C, LaForge K, Tian M, Melia D, Zhang S, Borg L et al (1998). Single-nucleotide polymorphism in the human mu opioid receptor gene alters beta-endorphin binding and activity: possible implications for opiate addiction. Proc Natl Acad Sci 95: 9608-9613.

Chick J, Anton R, Checinski K, Croop R, Drummond DC, Farmer R et al (2000). A multicentre, randomized, double-blind, placebocontrolled trial of naltrexone in the treatment of alcohol dependence or abuse. Alcohol Alcoholism 35: 587-593.

Crowley J, Oslin D, Patkar A, Gottheil E, DeMaria P, O'Brien C et al (2003). A genetic association study of the mu opioid receptor and severe opioid dependence. Psychiatr Genet.

DelBoca F, Kranzler H, Brown J, Korner P (1996). Assessment of medication compliance in alcoholics through UV light detection of a riboflavin tracer. Alcoholism: Clin Exp Res 20: 1412-1417.

Franke P, Wang T, Nöthen M, Knapp M, Neidt H, Albrecht S et al (2001). Nonreplication of association between mu-opioidreceptor gene (OPRM1) A118G polymorphism and substance dependence. Am J Med Genet 105: 114-119.

Gelernter J, Kranzler H, Cubells J (1999). Genetics of two mu opioid receptor gene (OPRM1) exon 1 polymorphisms: population studies, and allele frequencies in alcohol- and drugdependent subjects. Mol Psychiatry 4: 476-483.

Gianoulakis C (1996). Implications of endogenous opioids and dopamine in alcoholism: human and basic science studies. Alcohol Alcoholism 31(Suppl 1): 33-42.

Gianoulakis C, Krishnan B, Thavundayil J (1996). Enhanced sensitivity of pituitary beta-endorphin to ethanol in subjects at high risk of alcoholism. Arch Gen Psychiatry 53: 250-257.

Hernandez-Avila C, Wand G, Luo X, Gelernter J, Kranzler H (2003). Association between the cortisol response to opioid blockade and the Asn40Asp polymorphism at the mu-opioid receptor locus (OPRM1). Am J Med Genet 118B: 60-65.

Hoehe MR, Kopke K, Wendel B, Rohde K, Flachmeier C, Kidd KK et al (2000). Sequence variability and candidate gene analysis in complex disease: association of mu opioid receptor gene variation with substance dependence. 9: 2895-2908.

Jaffe AJ, Rounsaville B, Chang G, Schottenfeld RS, Meyer RE, O'Malley SS (1996). Naltrexone, relapse prevention, and supportive therapy with alcoholics: an analysis of patient treatment matching. J Consul Clin Psychol 64: 1044-1053.

King AC, Volpicelli JR, Frazer A, O’Brien CP (1997). Effect of naltrexone on subjective alcohol response in subjects at high and 
low risk for future alcohol dependence. Psychopharmacology 129: $15-22$.

Kranzler H, Modesto-Lowe V, VanKirk J (2000). Naltrexone vs nefazadone for treatment of alcohol dependence. Neuropsychopharmacology 22: 493-503.

Kranzler H, VanKirk J (2001). Efficacy of naltrexone and acamprosate for alcoholism treatment: a meta-analysis. Alcoholism: Clin Exp Res 25: 1335-1341.

Kranzler HR, Gelernter J, O’Malley S, Hernandez-Avila CA, Kaufman D (1998). Association of alcohol or other drug dependence with alleles of the $\mu$-Opioid Receptor Gene (OPRMI). Alcoholism: Clin Exp Res 22: 1359-1362.

Kreek MJ (1996). Opiates, opioids and addiction. Mol Psychiatry 1: 232-254.

Krystal JH, Cramer JA, Krol WF, Kirk GF, Rosenheck RA, Veterans Affairs Naltrexone Cooperative Study G (2001). Naltrexone in the treatment of alcohol dependence. New Engl J Med 345: 17341739.

Lahiri D, Schnabel B (1993). DNA isolation by a rapid method from human blood samples: effects of $\mathrm{MgCl}$, EDTA, storage time, and temperature on DNA yield and quality. Biochem Genet 31: 321-328.

Lichtermann D, Franke P, Maier W, Rao M (2000). Pharmacogenics and addiction to opiates. Eur J Pharmacol 410: 269-279.

McLellan A, Kushner H, Metzger D, Peters R (1992). The fifth edition of the Addiction Severity Index. J Subst Abuse Treatment 9: $199-213$.

McLellan AT, Luborsky L, Cacciola J, Griffith J, Evans F, Barr HL et al (1985). New data from the addiction severity index: reliability and validity in three centers. J Nerv Ment Dis 173: 412423.

McLellan AT, Luborsky L, O'Brien CP (1980). An improved evaluation instrument for substance abuse patients: the addiction severity index. J Nerv Ment Dis 168: 26-33.

Monterosso JR, Flannery BA, Pettinati HM, Oslin DW, Rukstalis M, O'Brien CP et al (2001). Predicting treatment response to naltrexone: the influence of craving and family history. $A m \mathrm{~J}$ Addict 10: 258-268.

Monti PM, Rohsenow DJ, Swift RM, Gulliver SB, Colby SM, Mueller TI et al (2001). Naltrexone and cue exposure with coping and communication skills training for alcoholics: treatment process and 1-year outcomes. Alcoholism: Clin Exp Res 25: 1634-1647.

Morris PL, Hopwood M, Whelan G, Gardiner J, Drummond E (2001). Naltrexone for alcohol dependence: a randomized controlled trial. Addiction 96: 1565-1573.

Murray C, Lopez A (1996). The Global Burden of Disease: A Comprehensive Assessment of Mortality and Disability from Diseases, Injuries, and Risk Factors in 1990 and Projected to 2020. Harvard University Press: Boston.

O'Malley SS, Jaffe AJ, Chang G, Schottenfeld RS, Meyer RE, Rounsaville B (1992). Naltrexone and coping skills therapy for alcohol dependence: a controlled study. Arch Gen Psychiatry 49: 881-887.

Oslin D, Liberto JG, O'Brien J, Krois S, Norbeck J (1997). Naltrexone as an adjunctive treatment for older patients with alcohol dependence. Am J Geriatr Psychiatry 5: 324-332.

Rommelspacher H, Smolka M, Schmidt L, Samochowiec J, Hoehe MR (2001). Genetic analysis of the mu-opioid receptor in alcohol-dependent individuals. Alcohol 24: 129-135.
Sander T, Gscheidel N, Wendel B, Samochowiec J, Smolka M, Rommelspacher $\mathrm{H}$ et al (1998). Human mu-opioid receptor variation and alcohol dependence. Alcoholism: Clin Exp Res 22: 2108-2110.

Schinka J, Town T, Abdullah L, Crawford F, Ordorica P, Francis E et al (2002). A functional polymorphism within the mu-opioid receptor gene and risk for abuse of alcohol and other substances. Mol Psychiatry 7: 224-228.

Smolka M, Sander T, Schmidt L, Samochowiec J, Rommelspacher $\mathrm{H}$, Gschiedel N et al (1999). Mu-opioid receptor variants and dopaminergic sensitivity in alcohol withdrawal. Psyhoneuroendocrinology 24: 629-638.

Sobell L, Sobell M, Gloria L, Cancilla A (1988). Reliability of a timeline method: assessing normal drinkers reports of recent drinking and a comparative evaluation across several populations. Br J Addict 83: 393-402.

Sobell LC, Sobell MB (1992). Timeline follow-back: a technique for assessing self-reported alcohol consumption. In: Litten R, Allen J (eds) Measuring Alcohol Consumption. Humana Press Inc.: Totowa, NJ. pp 41-65.

Streeton C, Whelan G (2001). Naltrexone, a relapse prevention maintenance treatment of alcohol dependence: a meta-analysis of randomized controlled trials. Alcohol Alcoholism 36: 544-552.

Szeto C, Tang M, Lee D, Stadlin A (2001). Association between mu opioid receptor gene polymorphisms and Chinese heroin addicts. NeuroReport 12: 1103-1106.

Thomas C, Wallack S, Swift R, Bishop C, McCarty D, SimoniWastila L (2001). Adoption of naltrexone in alcoholism treatment. J Addict Dis 20: 180.

Town T, Abdullah L, Crawford F, Schinka J, Ordorica P, Francis E et al (1999). Association of a functional mu-opioid receptor allele $(+118 \mathrm{~A})$ with alcohol dependency. Am J Med Genet 88: 458-461.

Volpicelli JR (1987). Uncontrollable events and alcohol drinking. Br J Addict 82: 381-392.

Volpicelli JR, Alterman AI, Hayashida M, O’Brien CP (1992). Naltrexone in the treatment of alcohol dependence. Arch Gen Psychiatry 49: 876-880.

Volpicelli JR, Davis MA, Olgin JE (1986). Naltrexone blocks the post-shock increase of ethanol consumption. Life Sci 38: 841847.

Volpicelli JR, O’Brien CP, Alterman AI, Hayashida M (1990). Naltrexone and the treatment of alcohol dependence: initial observations. In: Reid LD (ed) Opioids, Bulimia, and Alcohol Abuse \& Addiction. Springer-Verlag: New York. pp 195-214.

Volpicelli JR, Pettinati HM, McLellan AT, O'Brien CP (1997). BRENDA Manual: Compliance Enhancement Techniques with Pharmacotherapy for Alcohol and Drug Dependence. Guilford press: Philadelphia.

Volpicelli JR, Watson NT, King AC, Sherman CE, O'Brien CP (1995). Effect of naltrexone on alcohol 'high' in alcoholics. Am J Psychiatry 152: 613-615.

Wand GS, Mangold D, El Deiry S, McCaul ME, Hoover D (1998). Family history of alcoholism and hypothalamic opioidergic activity. Arch Gen Psychiatry 55: 1114-1119.

Wand GS, McCaul M, Yang X, Reynolds J, Gotjen D, Lee S et al (2002). The mu-opioid receptor gene polymorphism (A118G) alters HPA axis activation induced by opioid receptor blockade. Neuropsychopharmacology 26: 106-114. 